\title{
Los socios de los grupos de Sociedades Cooperativas: requisitos, condiciones
}

\author{
Carlos García-Gutiérrez Fernández \\ Redes de Micro organizaciones. Grupo Somosaguas. \\ Universidad Complutense. Madrid. www.ucm.es/info/rmgs/
}

Recibido: $\quad 15.07 .08$

Aceptado: 02.09 .08

Sumario: 1. Preámbulo.-2. Las cualidades de los socios de los grupos de sociedades cooperativas.-3. Los tres problemas de los conglomerados de sociedades cooperativas. - 4. La creatividad, la bondad y la generosidad.-5. Algunos métodos para fomentar los requisitos de los potenciales y reales socios.-6. Aplicación al caso de los socios de los grupos de sociedades cooperativas: el principio de la intercooperación.

\section{Preámbulo}

La mayor parte del tratamiento académico, del legislativo, de el biempensante y otras instancias, sobre el cooperativismo se fija, casi siempre, en la sociedad cooperativa. Pero no se presta a tención a lo esencial, a lo fundamental de la sociedad cooperativa: el socio.

Las sociedades cooperativas son empresas de empresarios (hacedores de riqueza, anticipadores del futuro, cambiandores de las restricciones, potenciadores de lo que les favorece) en democracia ${ }^{1}$.

Los socios de las sociedades cooperativas no lo son de una sociedad cooperativa, sino de una sociedad cuya vocación es la de serlo de un conjunto de sociedades. Al menos deben tener siempre presente.

1 García-Gutiérrez Fernández, C. La necesidad de la consideración de la sociedad cooperativa como entidad mercantil para la adecuada regulación. (El marco legislativo en materia de sociedades cooperativas en el reino de las autonomías de España. Un desatino del ordenamiento jurídico sin comparación en nuestro entorno cultural. Discusión de la conveniencia de tanto detalle en un contexto de economía global, de cara a la consolidación y fortalecimiento de las sociedades cooperativas). Revesco, n. ${ }^{\circ}$ 66, 1998, pp. 207-234. 
Por tanto, sus socios, que son lo único importante $-\mathrm{y}$ no la propia sociedad como quieren algunas administraciones públicas que maltratan a los socios con una legislación que los atenaza (aunque pueda parecer que es cosa de los poderes legislativos) - deben promoverse personalmente en la triple consideración de su participación en los procesos empresariales en los que están legitimados y, además, obligados²:

1. el de la toma de decisiones: ¡democráticamente! (al menos en el establecimiento de los objetivos),

2. el de producción y distribución — que es lo que les confiere la condición de socios como proveedores o como consumidores-y

3. el financiero —como banqueros con su, de ellos ${ }^{3}$, aportaciones al denominado jincorrectamente! «capital social»-

\section{Las perspectivas de la participación en la economía}

Las relaciones económicas han cambiado mucho; y van a cambiar más con base en la disponibilidad de información — como si se tratara de un bien libre- que tiene, como poco, los siguientes efectos:

- El desmantelamiento de las instituciones (incluyendo a los poderes públicos).

- Cada día es menos verdad que los poderes públicos ayudan: incluso, en muchas ocasiones, buscando (mantener) el poder tergiversan las ¿leyes? el recorrido económico y la propia regla de toma de decisiones ${ }^{4}$.

- La capacidad, de todos, de formarse expectativas.

En cualquier caso, en el mercado hay una alternancia, muy natural (que aplican muchos otros seres vivos como mecanismo de regulación vital) de competencia y cooperación.

Si, por ejemplo, dos mujeres, se encuentran hacen lo mismo que esos dos árboles que se plantan el uno vecino del otro: rivalizan y com-

2 García-Gutiérrez Fernández, C. El problema de la doble condición de los socios-trabajadores (socios-proveedores y socios-consumidores) ante la gerencia de la empresa cooperativa, Revista de Estudios Cooperativos (REVESCOO), Ns. 56 y 57, 1988-1989. pp. 83-121.

${ }^{3}$ García-GutiérRez Fernández, C. La reafirmación de las aportaciones (propiedad de) los socios de las sociedades cooperativas. Propuestas de regulación de las sociedades de responsabilidad limitada cooperativa. Revista de Estudios Cooperativos (REVESCO), n. ${ }^{\circ} 89,2{ }^{\circ}$ Cuatrimestre de 2006 (ISSN: 1885-8031). http://www.ucm.es/info/revesco/EdicionElectronica.php

4 Divar Garteizaurrecoa, Javier Poder económico y democracia en Ética y actividad empresarial / coord. por Pablo J. Beltrán de Heredia Iraurgui, 2004, ISBN 84-88123-46-9, pags. 25-32. 
piten por su hermosura o por el agua, respectivamente. Pero si una de las dos enferma, la otra le ayuda ¿por amor?, o porque necesita una competidora para ayudarse a sí misma.

\section{COROLARIO}

Se constata la existencia, crecimiento, consolidación y desarrollo de nuevas organizaciones privadas (particularmente en el ámbito de la información) con iniciativas que han estado reservadas a los poderes públicos limitados por las fronteras de su soberanía, que operan en el conjunto del mundo, y que se financian mediante sistemas de mercado, operando en el todo el mundo en esa que se ha dado en llamar economía global.

En un mundo en el que, como consecuencia de la disponibilidad - casi gratuita - de información, cada vez más las instituciones remiten y las organizaciones avanzan - pero no como una concesión sino como un derecho legítimamente conseguido-; en un mundo en el que la participación de las personas en la economía es cada vez mayor, los socios de las sociedades cooperativas deben asumir, promover y desarrollar su condición de empresarios mediante procesos eficientes de educación (que no sólo de formación o adiestramiento) o de asunción de criterios para la vida.

\section{Los cualidades de los socios de los grupos de sociedades cooperativas}

Las cualidades que deberían poseer los potenciales socios de las sociedades cooperativas cuando inician o se "adhieren» al proyecto empresarial que los convierte en protagonistas, en democracia, del hecho económico son dos:

1. La creatividad, que es consustancial al comportamiento de los empresarios (que no emprendedores) para ser empresarios, junto con otros empresarios en democracia.

2. La bondad y la generosidad — antropológica - (no se trata de la solidaridad que es proceso que abona las situaciones injustas) para coexistir, convivir, comprender, asumir y promover junto a los otros socios el propio proyecto en un mundo ya muy deteriorado en el que todas las personas tenemos la obligación de hacer cosas que nos favorezcan y que, simultáneamente, favorezcan a los demás (y no sólo por lo que afirma la sabiduría popular, por razones comerciales: "cosa regalada, cobrada y requetecobrada»). 
Estas cualidades deberían mantenerse permanentemente a lo largo del recorrido vital a través de las sociedades cooperativas que forman el grupo que:

1. ya existe previamente a su incorporación

2. se genera, con su concurso, para dar cumplimiento al principio de intercooperación.

\section{Los tres problemas de los conglomerados de sociedades cooperativas}

La sociedad cooperativa, como cualquier empresa (que es lo que, funcionalmente, es) tiene que crecer, innovar, ser competitiva, etcétera; para lo que tienen que conseguir equilibrios en la productividad, en la rentabilidad y en la eficiencia.

Pero, como sociedad, tiene tres problemas específicos.

1. La fata de asunción, por parte de los socios, de su condición de empresarios en democracia; por tanto, de participantes en todos los flujos de la empresa.

Hay que ser empresario antes que socio. Por tanto, hay que ser:

i. creativo; y además

ii. bueno y generoso (que no ético).

2. Subsiguientemente: por inhibición de los socios, la asunción de funciones, tareas y papeles por parte de la dirección que no les corresponde, abusando de una posición ejecutiva

3. La falta de procesos de concentración empresarial, incumpliendo el principio de intercooperación, de formación de redes empresariales, debido a:

i. La falta de motivación de los socios de serlo de un conglomerado cooperativo.

ii. El denominado «efecto agencia».

El resto de los problemas «típicos» que se concretan en la falta de competitividad: dificultades de financiación, ineficiencia productiva, etcétera, son consecuencia de los que se citan.

Por supuesto, no hay porque desconsiderar todas las subvenciones (de capital y de explotación) a la que se puede tener derecho, como cualquier empresa. Pero eso debe ser accesorio, colateral, subalterno, subsidiario, secundario. 
La sociedad cooperativa que reclama sus derechos antes que atender a sus obligaciones no es empresa ni sociedad cooperativa.

\section{Los tipos de personas}

Las personas (humanas, como algunos apostillan) somos muy complicadas. Somos únicas e irrepetibles; pero también sustituibles y re-emplazables (es decir: como afirma la sabiduría popular, cada uno: «no somos nadie $\left.{ }^{5}\right)$.

En todo caso, ya que no solo «la dona e mobile», sino también el hombre, somos incalificables y no encasillables. Sin embargo, en un determinado perido de tiempo podemos ser, por un lado, inteligentes o estúpidos; y, por otro, buenas o malas.

Al combinar esos dos criterios resulte algo tan sistemático como la siguiente clasificación de las personas ${ }^{6}$.

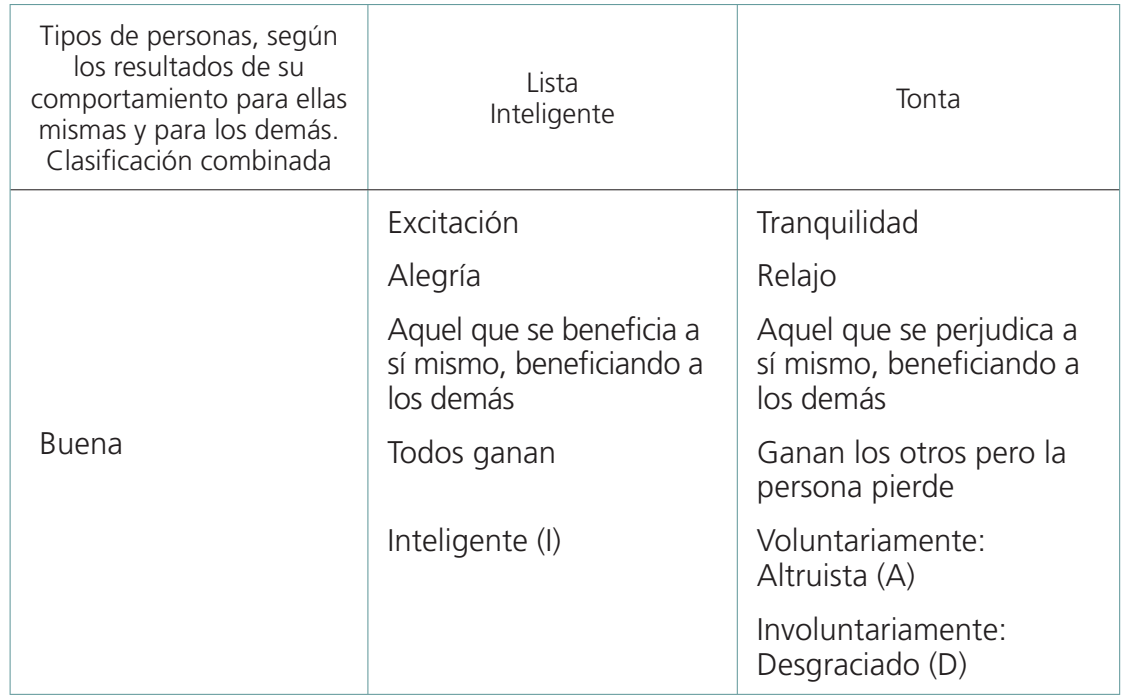

${ }^{5}$ La humanidad está compuesta, «a día de hoy», por más de 6.100 millones de personas.

${ }^{6}$ Según el historiador Carlos M Cipolla en 3. ${ }^{a}$ Ley. La ley fundamental o de oro. En Las leyes fundamentales de la estupidez humana. Allegro ma non troppo de 1988. http://www.eumed.net/curseco/economistas/Cipolla.htm\#completa Consultado el 10 de septiembre de 2005. 


\begin{tabular}{|c|c|c|}
\hline $\begin{array}{l}\text { Tipos de personas, según } \\
\text { los resultados de su } \\
\text { comportamiento para ellas } \\
\text { mismas y para los demás. } \\
\text { Clasificación combinada }\end{array}$ & $\begin{array}{c}\text { Lista } \\
\text { Inteligente }\end{array}$ & Tonta \\
\hline Mala & $\begin{array}{l}\text { Frustración } \\
\text { Aquel que se } \\
\text { beneficia a sí mismo, } \\
\text { perjudicando a los } \\
\text { demás } \\
\text { Gana la persona a } \\
\text { costa, explotando, } \\
\text { aprovechándose, } \\
\text { lucrándose a costa } \\
\text { de otros (pierden sus } \\
\text { ajenos) } \\
\text { Egoísta (E) } \\
\text { Bandido (B) } \\
\text { Juan PALOMO: «yo } \\
\text { me lo guiso, yo me lo } \\
\text { como» }\end{array}$ & $\begin{array}{l}\text { Depresión } \\
\text { Tristeza } \\
\text { Melancolía } \\
\text { Aquel que perjudica a } \\
\text { los demás y a sí mismo } \\
\text { Todos pierden } \\
\text { Estúpido (E) } \\
\text { Necio (N) } \\
\text { Ejemplo: el que ni come } \\
\text { ni deja comer a los } \\
\text { demás, que describiera } \\
\text { magistralmente D. } \\
\text { Félix LÓPE de VEGA y } \\
\text { CARPIO en «El perro del } \\
\text { hortelano» }\end{array}$ \\
\hline
\end{tabular}

De lo que se trata, el objetivo de cualquier política, planteamiento o estrategia es de que las personas seamos inteligentes: que lo que hagamos sea bueno para todos, sin distinción.

En efecto: como «una cosa lleva a la otra», como la acción lleva a una reacción, el estímulo lleva a la acción, el ejemplo es provocador; y como además, es precisa la combinación de competencia y colaboración, el modelo que hay que promover es la de la persona buena y lista.

\section{Nada es para siempre}

Como es sabido por la experiencia y como afirma la canción «nada es para siempre». Por eso, lo suyo, sería tener la capacidad de anticipa- 
ción que se tiene en los viajes (que son como la vida) en los que se conoce (al menos se estima) el destino y el momento de llegada.

Con carácter general, las relaciones personales funcionan bien si tienen un vencimiento que opera como una alerta que nos hace estar pendientes de la buena valoración que buscamos en los demás.

Cuando se asiste a un seminario o a un curso, se participa en un crucero, etcétera, todo suele ir bien: la convivencia está tasada. La causa es que hay un vencimiento, un final que descontamos y que controla nuestro comportamiento.

Sin embargo, cuando la relación no tiene fin predeterminado: cuando «es para siempre» las cosas son distintas. Es lo que ocurre con los matrimonios "hasta que la muerte les separe» (a los con-yuges) o con los con-sortes — con la misma suerte-, como es, particularmente, el caso de los socios de una sociedad cooperativa ya que la vinculación se asocia a la capacidad de participar en la actividad cooperativizada (lo cual no es el caso de los con-sortes por razón de capital financiero).

En efecto: se puede aplicar la analogía entre las relaciones societarias en las sociedades cooperativas y las relaciones matrimoniales, siquiera por lo que se refiere al compromiso. Por tanto, como éstas, deben basarse en lo mismo:

3. Ia creatividad para tener descendencia y asegurar su viabilidad

4. el amor para mantener la relación una vez que se cumple con la función biológica que es la que la origina

\section{El fenómeno de la inhibición y el consiguiente lucro}

Si se tiene la idea de que las cosas son «para siempre» se corre el riesgo de adocenarse ( «dos que duermen en el mismo colchón se vuelven de la misma condición»), de desconsiderar las actuaciones de los compañeros de viaje, de "abandonarse», de inhibirse, de encogerse de hombros, de dejar de valorar "lo que se tiene», con la consiguiente consecuencia que describe Joaquín SABINA cuando ya es demasiado tarde: «nada tan hermoso como lo que se ha perdido»

Cuando las relaciones de poder están equilibradas se puede tolerar un fallo, y dos, y alguno más; pero si se abusa, si hay una «manzana podrida», se produce un efecto de compensación mediante la inhibición con la que se persigue eludir o soslayar la explotación de los unos por los otros: el lucro.

Con tal de no sentirse explotados se produce un efecto imitación, el proceso se encadena, se enroca, suele ir a más; y, al final, todos salen perdiendo. 
En efecto, para la supervivencia de una sociedad cooperativa es condición necesaria, pero no suficiente un sistema justo de reparto de lo obtenido o de lo perdido (ningún socio explota a ningún otro socio: lo que permite afirmar que son empresas sin fin de lucro).

\section{La creatividad; y la bondad y la generosidad}

\section{La creatividad"}

Las motivaciones tienen efectos patentes en los comportamientos de las personas, pero la única fuerza de la que disponen las personas está en su interior.

Es preciso desarrollar la imaginación y aplicarla a tareas en las que el resultado ha de ser una aportación: los trabajos de investigación, de competencia, de descubrimiento, de creación.

La creatividad, la capacidad de crear, la desarrollan las personas que «hacen cosas»: buscan la verdad, la belleza o la riqueza, siguiendo un proceso análogo al de las madres creadoras de vida: dando a luz, desde su interior aquello que les caracteriza como creadores y quedando atrapados por el compromiso de su obra creada.

Partiendo de la base de que los procesos creativos se alimentan lo unos a los otros, lo ideal es que los creadores sean plurales. Por ejemplo, que los buscadores de riqueza - los empresarios - sean intrínsecamente artistas y filósofos (y viceversa).

\section{LA ILUSIÓN}

La vida se va minando, con el tiempo, con la frustración, con la desesperanza, con la des-ilusión.

Siempre: en todos los casos: en la investigación, en el arte, en los negocios, ... en el amor.

7 García-Gutiérrez Fernández, Carlos. García Villalobos, Juan Carlos. Fernández GuaDAÑo, Josefina. Miranda García, Marta Isabel. School of Co-operative-Studies at the Complutense University in Madrid. La creatividad como una específica categoría de cualquier clase de proceso. Su aplicación a las organizaciones (de producción) de participación. The Creativeness as an Specific Category in any Kind of Process. Its Appliance to the Organizations of Participation. El valor de la creatividad. Cultura emprendedora e innovación. 2004. Internacional Cooperative Alliance. European Conference. El Futuro De Las Cooperativas En Una Europa En Crecimiento. Organizadores locales: IUDESCOOP de la Universidad de Valencia y CIRIEC-España. Alianza Cooperativa Internacional. Comisión Científica. SEGORBE (Valencia) España, 6-9 de mayo de 2004. 


\section{LAS EXPECTATIVAS Y LA NECESIDAD}

Tiene que haber ilusión para que haya estímulo, y una actitud positiva. Pero, además tiene que haber necesidad de crear.

Para que haya movimientos; ¡cómo hacen los burros! que no se mueven ni siquiera aunque vean la zanahoria que se les pone delante: es preciso que tengan hambre.

\section{LA EMPRESA DE EMPRESARIOS}

La sociedad ha evolucionado mucho:

- los trabajadores estuvieron bajo el régimen de la esclavitud, como sistema de incorporación de la «cosa» humana a los procesos productivos,

- el feudalismo, en el que esas cosas eran denominadas siervos o vasallos,

- el movimiento obrero en la que ya eran «trabajadores», aunque en realidad hay que hablar de asalariados,

- la actualidad en la que se puede pronosticar la condición de empresarios $^{8}$ para los participantes en los procesos de producción de bienes y servicios -incluso los que se integran bajo la rúbrica de "asalariados», pero dentro de un mercado de trabajo global-.

La economía es cada vez más democrática atrayendo para sí lo que justifica y fundamenta la regla de una persona un voto, siquiera para establecer los objetivos de la organización en la que se participa. La base es, precisamente, la misma participación, como co-protagonistaen el proceso generador de riqueza.

\section{La bondad y la generosidad}

EL AMOR

«Hombres unidos de este modo, aunque en corto número, podrían en cierta manera vencer al mundo entero; .....

\footnotetext{
${ }^{8}$ No emprendedores, que es un eufemismo que se usa cuando implícitamente -e incorrectamente - se confunde al empresario con el capitalista; pero que no recoge la Real Academia de la Lengua.
} 
... porque no hay hombre tan cobarde a quien el Amor no inspire el mayor valor y no le haga semejante a un héroe. $»^{9}$

El amor y el odio es lo que, al menos entre los seres humanos, mueve el mundo: los mecanismos — coyunturales - para la vida y la muerte.

En realidad el único fin de cualquier cosa de la vida es la propia vida: la supervivencia. Los artistas buscan la belleza intrínseca de la vida (con sus lados oscuros y feos), los investigadores y filósofos buscan la ¿verdad? de la vida, y los empresarios «dan vida» a la vida.

Por eso se dice que las cosas se hacen por amor o por odio ( $j e l$ poder de la vida!).

Evidentemente, nada es comparable con la misma gestación de la vida; pero, como se sabe, esa función está exclusivamente asignada a las hembras en la casi todalidad de las especies animales.

\section{LA EXPERIENCIA Y LA CONSIGUIENTE SABIDURÍA (DE LA EXPERIENCIA)}

Con la experiencia que se gana con la edad se gana en sabiduría («más vale el diablo por viejo que por diablo») sin necesidad de ser político, ni directivo, ni dirigente, sólo un caminante de la vida. Por eso se llega a saber (con la sabiduría de la edad — valga la redundancia) — que:

- los genios son excepcionales; pero excepciones («hay que arar con los bueyes que se tienen»)

- hay que huir de los salvadores de la humanidad

- vale más el que es más bueno que el que es más listo o inteligente

- abunda la maldad, la ruindad, la necedad, la estulticia y la estupidez; y los que ni hacen ni dejan hacer

- cualquiera —absolutamente- puede llegar a ser la peor persona

\section{LA BONDAD Y LA GENEROSIDAD}

La bondad y la generosidad, siquiera como modo de ser especial, diferente, en el ámbito de lo económico, son particularmente necesarias, e incluso convenientes, para la humanidad.

${ }^{9}$ Del discurso de Fedro en El Banquete de Platón. AzCARATE, Patricio. Obras completas de Platón. Proyecto Filosofía en español (c) 2005 www.filosofia.org, Madrid 1871, tomo 5, páginas 297-366 
Se dispone de mucha información (incluso de estadisticas) sobre los desajustes, desequilibrios, ineficiencias y abusos que son consecuencias, precisamente, de comportamientos sociales, empresariales y macroeconómicos necios y egoístas.

Con la edad, se ven tantas cosas (ex-presidentes llevandole los papeles a hombres que llegan a ser la tercera fortuna del mundo en 20 años, directores de agencias financieras internacionales mediando en negocios, etcétera) que es casi una regla general que se llega a poderar a la generosidad y la bondad por encima de la inteligencia ${ }^{10}$.

\section{LA GENEROSIDAD}

La generosidad es un comportamiento natural; como la que se tiene con los hijos. El objetivo es que siga la vida. Es decir: no tiene que ver con la ética; sino con la supervivencia. sas $^{11}$ :

Hace falta la generosidad, entre otras cosas, para, entre otras co-

1. inhibirse de la mezquindad voluntaria o inconsciente de los otros

2. educar con la esperanza de que cunda el ejemplo

3. compensar la falta de productividad de los otros

4. vencer la desconfianzas

5. ganar las confianzas

6. asumir la explotación de los que «se encogen» de hombros

La creatividad y la generosidad

Es fácil constatar — basta con preguntar a los protagonistasque las personas más creativas suelen ser generosas. No sólo las madres, sino también los artistas que piensan que lo que hacen lo podría hacer cualquiera; o los investigadores que tratan de compartir sus descubrimientos y reflexiones; $y$, por supuesto los empresarios que conocen bien el fenómeno de la sinergia (dos más dos es igual a cinco), porque saben que su función de anticipación es tanto me-

10 Fernando ArRABAL (escritor de teatro español e iconoclasta, que se ha caracterizado por su anarquía, por ser estrambótico y por poner en entredicho lo establecido, es ponderado en Francia, que es un país que reconoce y valora a los intelectuales, vengan de donde vengan).

11 García-Gutiérrez Fernández, C.; García Villalobos, J.C.; Miranda García, M. La implicación personal en las decisiones que conforman la economía. Una aproximación. Sociotam. Vol. XV. Núm. 2. 2005. Pág. 103-115. 
jor cuanto más eficiente es la combinación que hacen de los factores productivos $^{12}$.

\section{LA BONDAD}

De poco vale que las personas sean emprendedoras, si no son buenas.

La bondad es una categoría que se puede establecer en términos económicos.

El altruismo recíproco, el comportamiento que beneficia la posición del otro sin esperar una recompensa inmediata (lo que no excluye que se espere) es practicado por especies muy evolucionadas como los delfines y los primates.

Sin embargo, la especie humana, supuestamente la más evolucionada, no la practica.

\section{La ética}

No hay que referirse a la ética, sino a la bondad.

La ética es una invención que es, en muchas ocasiones, contra natura. Es un sistema de regulación social complementario, sustitutivo; y, a veces, condicionante, del sistema legal convencional (el Código Civil español mantiene aún la referencia de la diligencia «como la de un buen padre de familia» con lo que da por bueno dos conceptos que hay en día están claramente revisados: la familia convencional y el machismo).

\section{La solidaridad}

No hay que confundirse ni confundir a los demás.

La apelación a la solidaridad, como si fuese una bandera a la que la falta de adhesión califica de in-solidario, y deja al que no la practica «fuera de juego»; pero es una trampa.

Clamar y promover la solidaridad conlleva abonar el «estado actual de cosas»: No hay que ser solidario, sino justo, como ha dicho repetidamente, y muy lúcidamente, Joan Manuel SERRAT y ¿GONZÁLEZ?

La estrategia correcta, con un claro sentido económico, es muy conocida y muy antigua: no hay que dar peces, sino enseñar a pescar; porque así el beneficiao se hace independiente del benefactor.

12 Tal y como describió el poeta uruguayo Mario BENEDETI con ese verso de amor... revolucionario: "porque unidos en la calle, codo a codo, somos mucho más que dos». 


\section{Algunos métodos para fomentar los requisitos de los potenciales y reales socios}

\section{La re-novación}

La ilusión está vinculada con la expectativa; la vocación de formar objetivos consistentes, naturales, con horizonte, con porvenir; y eso es propio, consustancial a la «juventud».

Manuel VICENT, columnista y escritor afirma que «se es joven mientras se tiene salud y proyecto».

Por eso, para no perder "el sentido de la vida» ${ }^{13}$ : hay que re-ilusionarse; y eso se consigue re-juveneciendo, renovándose.

\section{LA GENERACIÓN DE ILUSIONES, PERO, SOBRE TODO, VOLVER A CAMINAR}

Sólo los descerebrados ${ }^{14}$ no tienen ambiciones, ni proyectos, ni sueños, ni ilusiones, ni utopías porque, efectivamente, una de las funciones de la masa encefálica es, precisamente establecer el fin, los objetivos, las metas a lograr, sin las cuales no hay camino que hacer.

No hay que entender que por ser más realista se es un descerebrado; sino que la falta de ilusiones y de proyectos puede paralizar al afectado. Y, de ahí a dejar de utilizar el cerebro por aplicación de la sencilla regla de la evolución: «la función hace al órgano» 15

A esta situación se puede llegar, con el paso del tiempo (envejeciendo), por un proceso vegetativo previsible pero irremediable e irreversible; en el que, a cambio, se adquiere no sólo el conocimiento sino la sabiduría por:

1. errores cometidos atribuibles a uno mismo —porque sólo somos personas humanas y "nadie es perfecto».

2. la sucesiva acumulación de frustraciones causada por insatisfacciones ocasionadas por

13 Título de una famosa película de Monty Phytón.

14 No hay que fijarse sólo en el carácter descalificador con el que se tipifica a determinados individuos y grupos de individuos: a los que ni hacen ni dejan hacer.

15 Se puede aplicar, sin más que asociar organismo a organización la interesante teoría del famoso biólogo Jean Baptiste DE Monet, caballero de Lamarck (1744-1829), autor de entre otros, de Filosofía Zoológica que contiene la primera teoría científica de la evolución. 
a. actuaciones de el prójimo —o el lejano ${ }^{16}$-,

b. los resultados obtenidos - que no suelen ser, casi nunca, óptimos por los «imponderables» y los imprevistos-

Mientras tanto, hasta que se llega a ese estado de semi-inconsciencia, hasta ese Nirvana de inhibición nihilista-, las personas (humanas) nos diferenciamos del resto de los animales (sic) en que, al menos, mientras que somos jóvenes podemos autoengañarnos y autoproponernos utopías como horizontes inalcanzables a los que nos dirigimos con la esperanza de acariciarlas, arañarlas, agarrarlas o, quizás sería mejor decir: alcanzarlas; pero para comprobar, constantemente, sistemáticamente, impenitentemente que siguen alejándose; pero que sirven, como dice el cuentista uruguayo Eduardo GALEANO, precisamente ...... para caminar. Y esto es lo importante: el camino al que se refirió magistral y poéticamente Antonio MACHADO.

El cerebro humano funciona de esta manera - ¿distinta a la del resto de los seres vivos, al resto de los animales?-.

Es lo que utilizamos para tener ambiciones, proyectos, sueños, ilusiones, imaginación, ... para, en suma, tener otra vida (vale decir, vivir otra vida), personal pero distinta de la real.

\section{EL ESTABLECIMIENTO DE RETOS}

Ocuparse y preocuparse de asuntos que constituyan objetos de estudio y de atención (profesionales, empresariales, competitivos y personales) en el que subyacen ideas con vocación de transformación de las cosas es, por lo menos, significativo; por tanto, valorable, encomiable; y, en todo caso, gratificante.

\section{EL DESAFÍO DE LO DESCONOCIDO}

Eduardo PUNSET ${ }^{17}$ sugiere que, para que la vida tenga sentido hay que ser, siempre, un intruso: no conformarse con lo convencional: lo trillado, lo establecido, lo dominante. $Y$, señala que se es feliz cuando se pretende conseguir un objetivo alcanzable sometido a incertidumbre; que es lo que afirma la sabiduría china de manera más machista: el hombre feliz es el que se pone metas que puede alcanzar.

${ }^{16}$ Aún sin haber constatado que no había armas de destrucción masiva en Irak el mundo ha quedado convulsionado por la responsabilidad directa de políticos como George W. Bush en una crisis (no se entra aquí a valorar si ese argumento lo habría justificado siquiera).

17 Ex-ministro de la Unión del Centro Democrático, economista y filósofo. 


\section{LA PRACTICA DE LA INTERIOR TRASCENDENCIA}

La filosofía oriental conocida como yoga que genera tanto bienestar: paz, equilibrio, sensibilidad y amor por la vida, señala que hay que practicar la dicotomía:

1. el desapego y

2. trascender hasta el más allá (en el caso de la economía hacia los mercados globales -incluido el proveedor de la esquina y el cliente que es un vecino-).

\section{El método pedagógico}

\section{LA DISPONIBILIDAD DE INFORMACIÓN}

A través de internet se puede conseguir:

1. Formar expectativas

2. Revisar los valores

3. Equilibrar poderes

El mundo en el que nos encontramos, por tanto, ayuda a desarrollar la condición de empresario sin más que asomarse a la ventana electrónica y «navegar»; y eso explica el creciente número de iniciativas empresariales.

\section{EL ARTE COMO MODO DE CONOCIMIENTO}

El artista -el contemporáneo el de toda la vida-, cuando crea, analiza de otro modo distinto del científico, pero tan válido como aquel, la realidad.

En efecto, el arte es tan válido -en tiempos estaban unidas ciencia y arte- porque dispone su interior de conocimiento que le ha llegado de una manera ¿misteriosa? que explica la coincidencia (ausencia de plagio) entre, por ejemplo, Johanes VEERMER y Diego RODRIGUEZ de SILVA y VELAZQUEZ en el tratamiento de la luz; o entre Joaquín SOROLLA y Ignacio ZULOAGA en sus contrapuestos claros y oscuros; y así otras «causalidades» por el estilo con las que cabe argumentar precisamente eso: el misterio del conocimiento poseído y no aprehendido.

La ciencia, por el contrario explora, va hacia fuera del investigador. Requiere de la sistemática, del procedimiento, de la aplicación de alguno de los métodos «científicos» para llegar a conocer.

Es verdad que algunos científicos son unos «artistas» y que algunos artistas son muy técnicos; pero la diferencia está clara. 
Sea como fuere, la contemplación de las cosas identificando su característica artística contribuye a alentar el carácter creativo.

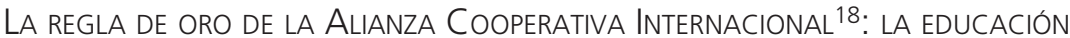

La educación es el proceso de mejora de una sociedad. Eso que tanta gente reclama haber recibido de sus padres o de sus familiares: «una buena educación».

Sin embargo, muchas personas no han tenido una buena educación. No sólo por lo que se refiere a las que demuestran un comportamiento soez, vulgar o desabrido: con falta de respeto a las otras personas, a los animales y a los seres vivos en general; sino por aquellas otras que apareciendo como «bien educados» son capaces de realizar acciones que les benefician a costa del perjuicio de terceros.

La educación es el proceso de transmisión de valores y de criterios; de establecimiento de actitudes de convivencia en busca dela armonía. Por eso, algunos autores denominan la regla de oro del cooperativismo al principio de educación.

Sin embargo, la formación es el proceso de transmisión de habilidades y de capacidades; aunque es cierto que la formación puede servir de soporte para la educación.

La aplicación, la traslación de la educación de cada uno a los demás, para entender sus modos de comportamiento puede adolecer del riesgo de presuponer que otros tienen el mismo sistema de valores ${ }^{19}$ (léase educación) y, de aquí, no entender ni (siquiera) comprender al prójimo.

\section{LA INTUICIÓN ADEMÁS DE LA FORMACIÓN}

El problema de la formación es que encorseta, encauza, encarrila, reconduce al discente en las doctrinas, ideología, sistemática y corriente

18 International Cooperative Aluiance. «The International Co-operative Alliance. Statement on the Co-operative Identity». En: XXXI Congress International Cooperative Alliance. U.K. Manchester, September 1996. Para un detalle ver Revista de Estudios Cooperativos (REVESCO), n. ${ }^{\circ} 61,1995$.

19 Divar Garteizaurrecoa, Javier y Gadea Soler, Enrique. «Los valores cooperativos y la participación de los trabajadores en la Empresa». Boletín de la Asociación Internacional de Derecho Cooperativo = Journal International Association of Cooperative Law, ISSN 1134-993X, N. 36, 2002 (Ejemplar dedicado a: Los Valores de la Cultura Económica Cooperativa), pags. 37-44. 
que subyace al mismo proceso de formación del que el docente es el soporte.

En efecto, la formación proporciona método (heurístico, inductivo, deductivo, lógico matemático, histórico, etcétera), la sistemática, el procedimiento, la organización de trabajo, etcétera.

Sin embargo, las personas que han hecho aportaciones relevantes, o siquiera sorprendentes, o posiblemente llamativas, o al menos rompedoras, o quizás novedosas, y en todo caso originales (de vuelta al origen) son las que están liberadas de esos cauces o raíles que proporciona lo convencional, lo establecido, lo guiado. Es decir, los que los han trasgredido aplicando su inteligencia emocional, y no solo la cerebral.

El método de la intuición, la frescura, la espontaneidad, el coraje, la corazonada, el «olfato» o lo «inexplicable»: la necesidad instintiva de, como hacen las mujeres, parir, gestar, crear, cuidar, y mantener lo creado.

Con todo, para que funcione el «método» de la intuición (para que los intuitivos hayan conseguido que sus verdades trasciendan y que ganen credibilidad; y viceversa) hace falta que haya:

- casualidades (que no causalidades) o

- esas personas han tenido que tener

- suerte (que es tan importante para casi todo en la vida); y,

- ser capaces de comunicar con habilidad (con mensajes que llegan a su destino) sus resultados.

— una sólida acumulación de esa formación convencional que proporciona método, sistemática, procedimiento y organización de trabajo.

Una empresa es un equipo y debe comportarse como tal: todos los elementos son fundamentales y ninguno sobra.

Es aquello atribuible a Pablo RUIZ PICASSO «la inspiración, cuando llega, te tiene que pillar trabajando».

\section{Aplicación al caso de los socios de los grupos de sociedades cooperativas: el principio de la intercooperación}

En el caso de las sociedades cooperativas los socios disponen de un marco empresarial y societario adecuado para ser

- Por un lado, creativos y

- Por otro lado, buenos y generosos. 
En efecto: se trata, precisamente la persecución del objetivo de la intercooperación que les obliga, como protagonistas, a tratar de sobrevivir como empresarios en democracia, adaptandose al mercado, acometiendo procesos de:

- crecimiento,

- concentración empresarial sin vinculación patrimonial

- concentración con vinculación patrimonial (fusiones o absorciones), ayudados por las necesarias segregaciones y escisiones

A través de ese mismo proceso, participando en él, democráticamente, se dan las condiciones para regenerar esos requisitos que han de tener los socios de las sociedades cooperativas con vocación de generar conglomerados:

1. La creatividad

2. La bondad y la generosidad 